\title{
Erratum to: ISCEV Standard for full-field clinical electroretinography (2015 update)
}

\author{
Daphne L. McCulloch • Michael F. Marmor • Mitchell G. Brigell • \\ Ruth Hamilton • Graham E. Holder • Radouil Tzekov • Michael Bach
}

Published online: 10 June 2015

(C) Springer-Verlag Berlin Heidelberg 2015

\section{Erratum to: Doc Ophthalmol (2015) 130:1-12 DOI 10.1007/s10633-014-9473-7}

There is an error in Table 1 of the recently published ISCEV Standard for full-field clinical electroretinography (2015 update) [1]. Users of this standard should note that the filter settings for dark-adapted oscillatory

The online version of the original article can be found under doi:10.1007/s10633-014-9473-7.

D. L. McCulloch ( $ه)$

School of Optometry and Vision Sciences, University of Waterloo, 200 University Avenue West, Waterloo,

ON N2L 3G1, Canada

e-mail: daphne.mcculloch@uwaterloo.ca

M. F. Marmor

Department of Ophthalmology, Byers Eye Institute, Stanford University School of Medicine,, Stanford, CA, USA

M. G. Brigell

Clinical Research - Ophthalmology, Aerpio Therapeutics, Cincinnati, OH, USA

R. Hamilton

Departments of Clinical Physics, Royal Hospital for Sick Children, NHS Greater Glasgow and Clyde, Glasgow, UK potentials (OPs), as correctly specified in the text, require that the high-pass filter should remove frequencies of $75 \mathrm{~Hz}$ and below from the ERG waveform; the low-pass filter setting of $300 \mathrm{~Hz}$ or above is the same as for other ERG tests. Table 1 is provided below with the correct bandpass for OPs

\author{
R. Hamilton \\ College of Medicine, Veterinary and Life Sciences, \\ University of Glasgow, Glasgow, UK \\ G. E. Holder \\ Moorfields Eye Hospital, London, UK \\ R. Tzekov \\ Department of Ophthalmology, University of South \\ Florida, Tampa, FL, USA \\ M. Bach \\ Section Visual Function, Electrophysiology, Eye Center, \\ Freiburg University, Freiburg, Germany
}




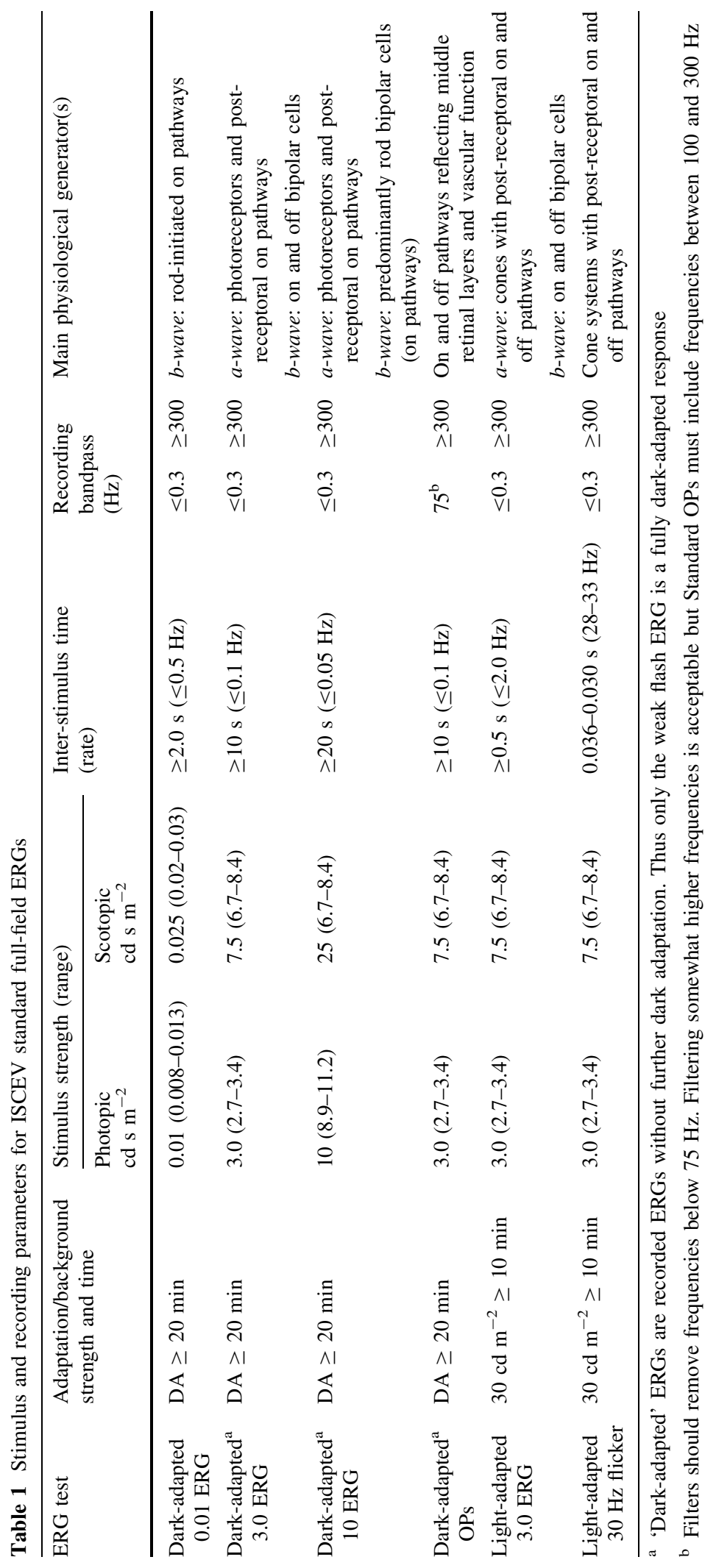




\section{Reference}

1. McCulloch DL, Marmor MF, Brigell MG, Hamilton R, Holder GE, Tzekov R, Bach M (2015) ISCEV Standard for full-field clinical electroretinography (2015 update). Doc Ophthalmol 130:1-12 